\title{
FACTORS AFFECTING STARTUPS SURVIVAL IN THE MENA REGION IN
} THE PRESENCE OF COVID19

\author{
NERMIN GOHAR ${ }^{1}$, HANY HANNA ${ }^{1,2}$, MAI H. HAROUN ${ }^{1}$ \\ ${ }^{1}$ Logistics of Supply Chain Department, College of International Transport and Logistics, Arab \\ Academy for Science, Technology and Maritime Transport, AASTMT, Alexandria, Egypt, e-mail: \\ hany.hanna@strath.ac.uk \\ ${ }^{2}$ University, Strathclyde College of Engineering, DMEM, Glasgow, UK
}

\begin{abstract}
A great percentage of the world economy is driven by entrepreneurs, start-ups and Small - and Medium - sized Enterprises (SMEs), as they are the driving forces of economic stability. This paper attempts to gain a full understanding of the environment in which entrepreneurs and SMEs operate; the so-called entrepreneurial ecosystem in MENA region to gather and collect information related to the needs examination on promoting entrepreneurial important criteria with the focus on Specific Region. The methodology proposed follows a qualitative approach using semi-structured interviews directed to owners and managers of startups in the MENA region. The process will be to observe, analyze, visualize the entrepreneurial ecosystem, including surrounding criteria's and factors that effects the startup survival. The proposed ecosystem is then 'mapped' to enable to see the gaps and constrains in the ecosystem in the MENA region, and to devise the most relevant measures to energize the ecosystem in MENA region. The proposed methodology and conceptual frame work not only will look at traditional indicators as business environment and investment climate, but also focus on creating optimal ecosystem that is well structured and ready for any unexpected events or occasions, like COVID19, which might have its impact on startups.
\end{abstract}

Keywords: Entrepreneurs in MENA, Entrepreneurial ecosystem, startups MENA region

\section{INTRODUCTION}

Entrepreneur is one of the most important inputs in the economic development of the country. Entrepreneurial competence makes all the difference in the rate of economic growth through creation of utility and generation of employment. Success of entrepreneurial activity, in any country, depends on a number of factors such as affluent natural resources, good infrastructure, availability of skilled labor, availability of adequate finance, wide market, advanced technology.

Government Policies in favor of entrepreneurs, talent, skill and ambitions of the entrepreneurs. This fact had been widely realized and accepted in the world today for the development of nations and it is an urgent need to find, nourish and develop competent entrepreneurship, if they want to achieve quick industrial development. Therefore, the paper investigates different factors affecting survival of entrepreneurial startups in the presence of the COVID19 event. The paper is divided into five sections; the first section is the current introduction, the second section presents the literature review for this research, the third section discusses the methodology followed for this research, the fourth section introduces the main research findings and finally, the fifth section presents the conclusion derived from this research.

\section{LITERATURE REVIEW}

This section discusses previous studies related to the entrepreneurial ecosystem, as well as startups survival criteria. 


\section{Entrepreneurial Ecosystem}

As a multidisciplinary field of study (Parker, 2009) that involves economics, management, social science and anthropology (Ahmed and Seymour, 2008), there exists several definitions of entrepreneurship, each carries a slightly different perspective and scope. The 1997 Organization on Economic Cooperation and Development (OECD) survey defined entrepreneurship as "The dynamic process of identifying economic opportunities and acting upon them by developing producing and selling goods and services". Therefore, entrepreneurship was considered to be as an engine of economic growth and it is related to a combination of several determinants such as education levels, business climate and legal and political conditions (Alvarez et al., 2014).

Additionally, based on the systems approach by Acs et al. (2014), entrepreneurship is an action undertaken and driven by agents on the basis of incentives. It provides civilization with an enormous amount of goods and services and enhances the growth of social welfare. Furthermore, the main importance of entrepreneurship is the creation of job opportunities, innovation, and improve the economy. In addition, entrepreneurship is central to achieving those national objectives for several reasons for instance, Entrepreneurship improves productivity, spurs innovation and creates jobs.

To realize growth and innovation, the ecosystem must function well for entrepreneurs. Such an "entrepreneurial ecosystem" is an interactive network of actors who influence each other and the chances of survival of a venture creator and his company in a region or country (Stam, 2016). In addition, the competencies of a business owner, networks, formal institutions, human capital and culture, new knowledge, and financing are also crucial for value creation from entrepreneurship. The challenge is to let all these elements complement each other in such a way that together, they provide more value. That is what characterizes a well-functioning ecosystem. Hence, the Entrepreneurship Ecosystem is therefore complex. So, what is essential is not only data at the macroeconomic level but also at the individual level.

Furthermore, Coordination among the various actors for an adequate functioning of the startup ecosystem is one of top priorities that needs to be resolved in order to create and maintain a well-functioning environment for startups and new businesses. Until recently, there was no relevant institution (ministry) fully dedicated to innovation and entrepreneurship that would be entirely responsible for regulating such ecosystem and bridging actors towards an effective synergy. Other organizations had to intensively engage in coordinating close cooperation among the actors, since the Ministry of Innovation and Entrepreneurship has been recently established.

Micro, small and medium-sized enterprises (MSME) are considered the backbone of local and global businesses. Globally, it constitutes around $90 \%$ of all firms and around $60-70 \%$ of total employment. In Developing countries, the MSME contribute to $99 \%$ of private enterprises according to recent research. Thus, developing countries usually view MSMEs as a dynamic force for sustained economic growth and job creation.

\section{Startups Survival Criteria}

The Middle East and North Africa (MENA) region is vast, rapidly transforming and heterogeneous. Since 2011, the region has experienced an eruption of conflict in several Arab countries. Startup companies support economic development through growing on the market and thus generating economic growth and employment opportunities for the country.

https://doi.org/10.24264/icams-2020.III.6 
A startup, as such, represents a newly emerged business venture that has the intention of developing a feasible business model in order to meet the needs of a society by creating a virtuous cycle that derives constant improvement through innovative solutions. A startup therefore, fits best in developing economies whose main objective is to reduce poverty and generate sustainable wealth through innovative solutions that are able to solve industry-wide problems. Hence the startups in MENA regions need a specific ecosystem and criteria to support its survival and existence. Besides, it is also essential to understand the problems facing small business development in MENA region because they are significantly different and unique from those being faced in developed countries (Okpara and Wynn, 2007). The Problems facing the growth and survival of Startups can be generally classified as follows:

- Regulatory Administrative: Boundaries for entry

- Market Conditions: Competition

- Access to finance and fund: lack of capital and investments

- Knowledge creation and diffusion: Technological operations

Another acknowledged factors which negatively affect small business development include corruption, poor infrastructure, poor location, failure to conduct basic market research, and the economy (Tushabomwe-Kazooba, 2006; Mambula, 2002). Therefore, we must understand and notice that, lacking of the previous criteria and influencing factors the startups cannot easily survive and maintain. Also, very specified criteria that must be available in the ecosystem to help startups in the MENA region to survive and cope with the dynamic growth within starts up, thereby increasing effectiveness and efficiency in the economy.

Recently a further shortcoming, during the pandemic of (COVID-19) crisis, start-ups have continued to play a critical role for economies. Some innovative young firms have reacted fast and flexibly to the pandemic, and have been critical in helping many countries shift towards fully-digital work, education, and health services, and have provided innovations in medical goods and services. At that time marked by significant economic uncertainty and with their revenues affected by containment measures and significant drop in demand, start-ups may become even more financially fragile and will need support for their short-term liquidity needs, critical for their survival. Hence, this un expected event proofs that a healthy ecosystem contains the survival elements to provides actual business support.

\section{RESEARCH METHODOLOGY}

This research follows the qualitative approach, as a semi-structured interview was designed to explore the factors affecting startups survival in the presence of COVID19. The interview was directed to owners and managers of startups in the MENA region, where a number of 30 responses were collected. Respondents include males and females from the age group of 30 to 45 years old who belong to different countries of the MENA region. Analysis was done using NVIVO, version 12, by first describing the approach to interview analysis, then identifying the interviews procedures, and finally, identifying the coding process followed in the analysis process. Therefore, data was extracted in the form of codes and nodes. 


\section{FINDINGS AND DISCUSSION}

This section discusses the main results of the qualitative analysis of the in-depth interview conducted with managers and owners of startups in the MENA region. Examining the data inductively allowed the researcher to organize the data into concepts and elements that link them together. Breaking down the data gives the way to the understanding of the data and explain the emerging patterns. Then the researcher is able to bring together bits of theory from the interpretation of these patterns. The final themes that emerge from the content analysis establish answers for the research.

The interview is divided into sets of semi structured questions that are related to the factors affecting startups survival. Based on the observed themes, there are some important factors obtained, which are: Government Policies, Barrier of Entry, Access to finance and fund, and Technological operations. They are described in details, according to their rank of importance to respondents of interview, as follows:

\section{Theme 1: Technological Operations}

Almost all respondents agree that technology becomes the most important factor for their business. They claim that, in the presence of COVID19, technology could help in reducing fixed cost and even some variable cost that they bear. One evidential quote is "After COVID19, we rely on teleworking and we have all our meetings online. I become able to reduce rental cost by relying on virtual work".

\section{Theme 2: Financing}

Majority of respondents agree that having enough fund is very important, as they might need to pay salaries to employees, while there is no income, in order to avoid losing those employees. One evidential quote is "At the first instance of COVID19, I was obliged to give long vacation to employees, with normal salaries. So, you should have enough financing to face unexpected events, otherwise, you will fail".

\section{Theme 3: Government Policies}

Majority of respondents agree that government policies is a major factor that influence their business. One evidential quote is "I was obliged to close my business during COVID19 by government regulation, which causes my failure!".

\section{Theme 4: Market Conditions}

Majority of respondents agree that market conditions had been dramatically changing in the presence of COVID19. One evidential quote is "Only necessary products find their ways in the market during COVID19, while luxurious ones are present in the market only through online channels".

Other themes that evolve were regulatory administrative, Turnover, Innovation, education, but they come in the rank after the above-mentioned themes.

\section{CONCLUSION}

There are several factors that affect startups in the MENA region nowadays, which could be listed as follows: Access to finance and fund, market conditions, regulatory administrative, Government policies, Turnover, Innovation and education. These factors 
were showing up with different importance to startups before COVID19. After such event, technological operations become the most superior factor to these ones for startups. A great attention should be devoted to technology when starting your business, as it could be the best way of communication with employees as well as customers.

\section{REFERENCES}

Abu Bakar, A.R., Ahmad, S.Z., Wright, N.S. and Skoko, H. (2008), "The propensity to business startup: Evidence from Global Entrepreneurship Monitor (GEM) data in Saudi Arabia", Journal of Entrepreneurship in Emerging Economies, 9(3), 263-285, https://doi.org/10.1108/JEEE-11-2016-0049.

Acs, Z.J., Autio, E. and Szerb, L. (2014), "National system of entrepreneurship: Measurement issues and policy implications", Research policy, 43, https://doi.org/10.1016/j.respol.2013.08.016.

Ahmad, N. and Seymour, R.G. (2008), "Defining Entrepreneurial Activity: Definitions Supporting Frameworks for Data Collection", OECD Statistics Working Paper, 5-6.

Alvarez et al. (2014), "Building Understanding of Smart City Initiatives", Lecture Notes in Computer Science, $7443,40-53$.

Mambula, C. (2002), "Perceptions of SME Growth Constraints in Nigeria", Journal of Small Business Management, 40(1), 58-65, https://doi.org/10.1111/1540-627X.00039.

Okpara, J.O. and Wynn, P. (2007), "Information Technology and the challenges of Economic Development", in: African E-Markets Information and Economic Development, Economic Commission for Africa.

Parker, D. (2009), “The magnitude and causes of agglomeration economies", Journal of Regional Science, 50(1), 203-219, https://doi.org/10.1111/j.1467-9787.2009.00657.x.

Stam, E. (2015), "Entrepreneurial ecosystems and regional policy: a sympathetic critique", European Planning Studies, 23(9), 1759-1769, https://doi.org/10.1080/09654313.2015.1061484.

Tushabomwe-Kazooba, C. (2006), "Causes of Small Business Failure in Uganda: A Case Study from Bushenyi and Mbarara Towns", African Studies Quarterly, 8(4).

*** (2018), "For Entrepreneurship and Innovation Ecosystem Leaders: A Step-by-Step Country Master Plan to Create and Drive a Healthy Early Stage Investment. Market for Your Country/Region, http://wbaforum.org/for-entrepreneurshipinnovation-ecosystem-leaders/index.html. 
Factors Affecting Startups Survival in the MENA Region in the Presence of COVID19 